Научная статья

УДК 347.611 .1

DOI 10.18101/2658-4409-2021-4-16-22

\title{
ПРАВОВОЕ РЕГУЛИРОВАНИЕ ВОПРОСОВ РЕИНКАРНАЦИИ БУДДИЙСКИХ ЛАМ В КНР: ИСТОРИКО-ПРАВОВОЙ АСПЕКТ
}

\author{
(C) Гунзынов Жаргал Паламович \\ старший преподаватель, \\ Бурятский государственный университет имени Доржи Банзарова \\ Россия, 670000, г. Улан-Удэ, ул. Смолина, 24а \\ gzzrl@yandex.ru
}

\begin{abstract}
Аннотация. Статья посвящена историческому анализу правового регулирования вопросов реинкарнации буддийских лам в Китае. Автор анализирует разные исторические эпохи и связанные с ними правовые акты, посвященные данному вопросу, основные причины внимания китайского руководства к религиозным вопросам.

Изучение данного вопроса представляет интерес как пример законодательного регулирования сугубо религиозных вопросов, истинная природа которых остается до конца не изученной, но при этом имеющей большое влияние на государственную и общественную жизнь.
\end{abstract}

Ключевые слова: реинкарнация, буддийское право, Далай-лама, Панчен-лама, право Китая.

\section{Для цитирования}

Гунзынов Ж. П. Правовое регулирование вопросов реинкарнации буддийских лам в КНР: историко-правовой аспект // Вестник Бурятского государственного университета. Юриспруденция. 2021. Вып. 4. С. 16-22.

Одной из центральных идей буддизма является идея реинкарнаций - перерождений всех живых существ, находящихся в сансаре. Буддийская философия связывает причину этого с омраченностью сознания живых существ, из-за чего они не могут выйти из сансары, обретая новые рождения и заново переживая страдания живых существ. При этом, согласно буддийскому мировоззрению, есть единственный способ выйти из сансары - это достичь состояния просветления, т. е. состояния сознания, освобожденного от всех омрачений. Достичь этого невозможно без духовных наставников - лам, многие из которых считаются живым воплощением Будд и Бодхисатв, которые достигли просветления, но добровольно остались в сансаре, чтобы, перерождаясь, из жизни в жизнь продолжать даровать Учение Будды дхарму, таким образом, давая возможность другим живым существам также достичь просветления.

Ярким воплощением указанной концепции является институт далай-лам как духовных лидеров буддистов всего мира. Выделяются также иные буддийские иерархи, каждый из которых считается перерожденцем предыдущих великих буддийских лам. Очевидно, в силу своего статуса все они имеют огромное влияние на священнослужителей и верующих, могут стать активным участником общественных и политических процессов. Это можно видеть из истории Тибета, где Далай-ламы фактически являлись и главами государства. Это продолжалось 
Ж. П. Гунзынов. Правовое регулирование вопросов реинкарнации буддийских лам в КНР: историко-правовой аспект

до 1959 г., когда после военного вторжения Китая правительство Тибета во главе с Далай-ламой XIV бежало в Индию.

Однако и помимо Далай-ламы в Тибете, который многие столетия является центром мирового буддизма, существовали традиции институтов других ламперерожденцев или, как их принято называть в зарубежной литературе, «живых Будд» (тиб. Тулку; кит. 活佛 huo fu). Безусловно, китайское правительство понимало значение данного вопроса, в том числе и для эффективного государственного управления в Тибете, поэтому неудивительно, что так называемый «тибетский вопрос» касался и многих религиозных аспектов.

В последнее время вопрос о реинкарнации лам снова набирает свою актуальность в силу преклонного возраста Далай-ламы XIV. В своих интервью он неоднократно допускал, что следующий Далай-лама может родиться за пределами Китая и Индии и необязательно он будет тибетцем. Также он говорил, что в целом стоит вопрос о том, необходимо ли сохранить институт Далай-лам в будущем ${ }^{1}$.

Исторически первое закрепление институт перерожденцев получил в таком направлении буддизма, как Карма Кагью. В период существования Монгольской империи различные тибетские буддийские направления сталкивались со все более ожесточенной конкуренцией по религиозным и политическим вопросам. Ocновываясь на буддийских теориях взаимозависимого происхождения (Pratītyasamutpāda), возрождения (Samısāra) и трех тел (Trikaya), Карма Пакши (тиб. गғ च, 1204-1283), лидер Карма Кагью создал линию Кармап (тиб. 함) линию преемственности духовных наставников, первую систему реинкарнации живых Будд [2]. Новая система упразднила преобладавшую на тот период методику выбора преемников лам либо на основе отношений «учитель — ученик», либо на основе родства и разработала религиозные ритуалы для поиска преемника «ян шрид» (тиб. yang srid), который станет следующим Кармапой, главой сек-

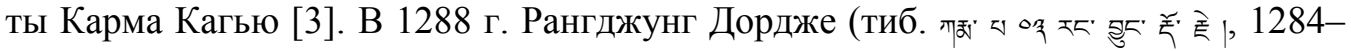
1339) был признан преемником Кармапы и стал первым реинкарнированным «живым Буддой» в истории [4].

С тех пор различные школы тибетского буддизма стали перенимать опыт Карма Кагью и создали свои системы реинкарнаций лам. Со временем самой влиятельной стала линия преемственности далай-лам и панчен-лам. В начале XVII в. широкую популярность стала набирать школа Гелуг. Происходило это во многом благодаря поддержке Хошутского ханства. На ранних этапах в школе Гелуг также применялся метод передачи «учитель — ученик», однако, по мнению ряда исследователей, такая система нередко ставила под сомнение авторитет духовных лидеров, особенно в политических вопросах. Таким образом, школа Гелуг установила линию преемственности далай-лам в 1474 г. и линию преемственности панчен-лам в 1645 г. на основе поиска их реинкарнаций [5].

К слову, идея тулку получила свое распространение и в других государствах. Так, при поддержке пятого Далай-ламы Нгава́нг Лобса́нг Гьяцо́ (1617-1682 гг.) в

\footnotetext{
${ }^{1}$ Новое воплощение // Выступление Далай-ламы XIV. URL: https://ru.dalailama.com/the-dalai-lama/biography-and-daily-life/reincarnation (дата обращения: 20.11.2021). Текст: электронный.
} 
Монголии был учрежден институт богдо-гэгэн. Первым богдо-гэгэном стал сын монгольского Тушэту-хана Гомбодоржа Дзанабадзар (1635-1723), которого признали перерождением Таранатхи - одного из крупнейших тибетских мыслителей и религиозных наставников [6].

Влияние буддийских иерархов постепенно стало распространяться не только на духовную жизнь, но и на иные сферы жизни общества. Они становились важной политической фигурой. В частности, в середине XVII в. Тибет фактически стал теократическим государством, главой которого был Далай-лама. Это не могло не отразиться и на правовом регулировании вопросов реинкарнации лам.

Исторически первый способ урегулировать отношения с тулку сформировался в период Монгольской империи. Между монгольскими правителями и духовными лидерами Тибета сформировалась особая система распределения полномочий - йончо (тиб. жб̌г гัб, Yönchö). Светский режим отвечал за политические, экономические и военные дела, а тибетские религиозные лидеры - за духовные и религиозные вопросы.

Позднее в XVII в. власть над Тибетом установила династия Цинь. Именно в этот период были приняты первые законодательные акты, которые в достаточной степени полно регулировали духовную жизнь, в том числе и вопросы, связанные с реинкарнацией лам. Династия Цин последовательно обнародовала шесть законов об управлении Тибетом и три постановления об управлении ламами (монахами и «живыми Буддами»), включая Постановление «О более эффективном управлении Тибетом» (кит. 酌定 西藏 善後 章程 十三 條, 1751 г.); постановление «О создании и разграничении станций» (кит. 設站定界 事宜十九 條, 1789 г.), постановление по тибетским вопросам (кит. 酌 議 藏 中 各 事宜 十條, 1790), дополненное в 1793 г.; постановление «О запрещении накопленных злоупотреблении в Тибете» (кит. 酌擬裁禁的上積弊章程二十八條, 1844), Новый план тибетской политики (кит. 新治藏 政策 大綱, 1907), Положение Ли Фань Юань - 5-томные правила лам (кит. 理藩院 則 例 : 喇嘛 事例 五卷), Монгольский кодекс - Положение ламы (кит. 蒙古 律例 — 喇嘛 例), Собрание статутов династии Цин - Положение об ограничениях для лам (кит. 大清會典事例 喇嘛 禁令) [7]. Эти законодательные акты установили относительно полную систему правового регулирования тибетского буддизма, которая включила в себя управление храмами и монастырями, поиск и идентификацию перерожденцев высокопоставленных лам и великих живых будд, а также систему управления поведением лам в повседневной жизни и т. д.

Несмотря на попытку внести определенную четкость в вопросах регулирования процедуры признания реинкарнации великих лам, неизбежны были и попытки манипуляций данным процессом. По сути, поиски и установление перерожденцев стали острым политическим вопросом, в решении которого были заинтересованы самые разные политические силы. Чтобы нивелировать все разногласия в 1793 г. был законодательно закреплен метод «Золотая урна», с помощью которого необходимо было находить перерожденцев великих лам. Процедура представляла из себя следующее:

1) на первом этапе определялось несколько кандидатов в преемники; 
Ж. П. Гунзынов. Правовое регулирование вопросов реинкарнации буддийских лам в КНР: историко-правовой аспект

2) имена преемников и их годы рождения записывались на бланках из слоновьей кости на маньчжурском, китайском и тибетском языках;

3) после этого все почтенные тулку должны были молиться 7 дней;

4) далее из урны вынимался случайным образом бланк с именем одного из кандидатов. Он и признавался официально новым тулку [8].

Помимо метода Золотой урны вводилась и система государственной регистрации лам-перерожденцев - Ду Дие (кит. 度牌, «свидетельство монаха»). Ламам выдавался сертификат о признании их тулку или преемником предыдущего ламы. В последующем на рубеже XVII-XVIII вв. принимается система Сань Цзы (кит. 僧 籍, «членство в буддийской общине»). Согласно этой системе все буддийские монахи прикреплялись к монастырям и монастыри должны были производить регистрацию всех перерожденцев. В 1820 г. тибетское правительство начинает вести реестры тулку.

Стоит отметить, что в последующем метод Золотой урны применялся нерегулярно. Согласно историческим записям, с 1793 по 1910 г. с помощью Золотой урны было установлено 76 реинкарнаций. Это очень незначительное количество из общего числа перерожденцев, которых за этот период насчитывается несколько тысяч [9].

Далай-лама XIV в. своем выступлении отмечал: «В результате данная процедура была применена в отношении некоторых реинканаций Далай-ламы, Панченламы и других высоких лам. Указ о соблюдении этого ритуала был подписан Восьмым Далай-ламой Джампелом Гьяцо. Однако уже после введения этой системы данная процедура не применялась при установлении IX, XIII и меня самого, XIV Далай-ламы.

А что касается Далай-ламы X, то его подлинная реинкарнация была найдена и подтверждена без применения Золотой урны, но, чтобы угодить маньчжурам, было объявлено о том, что процедура была соблюдена. Таким образом, Золотая урна в действительности использовалась лишь для определения XI и XII Далайлам. Однако Далай-лама XII был признан еще до проведения процедуры. Так что имел место лишь единичный случай, когда Далай-лама был распознан с помощью этого способа.

Подобным образом, из Панчен-лам посредством Золотой урны были определены только VIII и IX и более никто. Эта система была навязана маньчжурами, но тибетцы не питали к ней веры, поскольку не видели в ней никакой духовной силы. Однако, если подходить к ней честно, то в ней можно усмотреть сходство с гаданием на шариках из теста (зен-так)» [10].

Таким образом, несмотря на законодательное закрепление, метод Золотой урны на практике не стал основополагающим и не заменил собой религиозные ритуалы, направленные на поиск и установление лам-перерожденцев. В большинстве своем применяли традиционные буддийские методы, связанные с пророчествами буддийских лам, оракулов и т. д.

После провозглашения Китайской народной республики в 1911-1913 гг. вопросы религии, в частности буддизма, не потеряли для Китая своей актуальности. Одним из самых острых вопросов политической повестки того времени для нового китайского правительства стала проблема удержания в составе государства Монголии и Тибета. Для решения проблемы в 1912 г. было учреждено 
Агентство по делам Монголии и Тибета, которое в 1929 г. реорганизовали в Комиссию по делам Монголии и Тибета. К 1938 г. этим органом власти было издано 190 постановлений по различным вопросам, связанным с Монголией и Тибетом, из них 24 напрямую касались буддизма в Тибете. Среди них Положение об управлении храмом лам, Поправка к мерам по регистрации лам, мерам по назначению лам и мерам по вознаграждению и наказанию лам и т. д.

Особняком в этом перечне стоит принятый в 1936 г. Закон о мерах по определению реинкарнаций лам. Он во многом закрепил существовавший во времена Цинской династии порядок определения реинкарнаций лам с помощью Золотой урны, закрепил процедуру признания перерожденцев живых Будд, религиозные титулы, делопроизводство в храмах и т. д.

Однако, несмотря на все эти законодательные меры, их реальное влияние на тибетский буддизм оставалось минимальным. Играли свою роль сепаратистские настроения в Тибете, а также японское вторжение, которое значительно ослабило власть китайского правительства (Гоминьдана) в целом по всей стране. Фактически, можно говорить, что в период с 1911 по 1951 г. Тибет де-юре был частью Китая, но на самом деле обладал значительной автономией, позволявшей называть его независимым государством.

Ситуация поменялась после прихода к власти Коммунистической партии. После военного вторжения и присоединения Тибета в 1951 г. китайское правительство вновь серьезно взялось за решение «тибетского вопроса». Историки выделяют здесь три этапа:

- 1951-1959 гг. Теократический характер управления в Тибете, традиционный уклад экономики, основанный на сельском хозяйстве, а местами даже и на помещичьем укладе, сохранялся;

- 1959-1982 гг. Период Культурной революции. Многие религиозные учреждения, храмы и монастыри были упразднены и разрушены. Многие религиозные деятели были репрессированы ${ }^{1}$;

- с 1982 г. по настоящее время. В 1982 г. официально было объявлено о завершении Культурной революции. После этого Коммунистическая партия Китая (КПК) ослабила контроль над религией. После окончания культурной революции в марте 1982 г. КПК официально отказалась от своего полного запрета на религию, выпустив документ Центрального комитета под названием «Основные взгляды и политика по религиозному вопросу в период социализма в нашей стране». В документе провозглашается, что основная политика КПК в отношении религиозного вопроса заключается в уважении и защите свободы вероисповедания, и говорится, что «для обеспечения дальнейшей нормализации религиозной деятельности правительство должно в дальнейшем на основе консультаций с религиозными деятелями разработать реалистичное законодательство, которое возможно будет реализовать на практике».

Выбранный политический курс дал начало целой волне принятия нормативноправовых актов. В настоящее время в Китае создана обширная правовая база по

\footnotetext{
${ }^{1}$ Новое воплощение//выступление Далай-ламы XIV. URL: https://ru.dalailama.com/thedalai-lama/biography-and-daily-life/reincarnation (дата обращения: 20.11.2021). Текст: электронный.
} 
Ж. П. Гунзынов. Правовое регулирование вопросов реинкарнации буддийских лам в КНР: историко-правовой аспект

вопросам религии, включая Положение по делам религий и 8 административных правил по управлению религией.

Среди них и приказ Государственного комитета по делам религии КНР «О мерах по управлению реинкарнациями живых Будд в тибетском буддизме», изданный 13 июля 2007 г., который является первым и единственным специальным нормативно-правовым актом, устанавливающим правовое регулирование реинкарнации живых Будд и впервые подводит все традиции линий преемственности буддийских лам под принципы права. Данный документ утверждает порядок установления и утверждения лам-перерожденцев, обязанности буддийских общин по воспитанию и обучению преемников великих лам, а также меры ответственности за нарушение установленных правил ${ }^{1}$.

Особый интерес представляет порядок признания реинкарнаций лам, установленных в указанном приказе. Процедура возможна при наличии следующих условий:

во-первых, в поиске перерожденца заинтересовано значительное число верующих и священнослужителей;

во-вторых, «линия преемственности» тулку должна быть непрерывной и продолжаться до нашего времени;

в-третьих, в Государственный комитет по делам религии должна быть подана заявка на утверждение новой реинкарнации ламы от имени монастыря, имеющего соответствующую лицензию на поиск и воспитание тулку ${ }^{2}$.

При этом в процедуре поиска реинкарнаций главную роль играют религиозные ритуалы, которые используются в буддизме испокон веков. Единственное исключение - поиск реинкарнаций далай-лам и панчен-лам, которые должны утверждаться по методу Золотой урны.

Таким образом, вопросы правового регулирования различных вопросов, связанных с буддизмом в Китае, имеют давнюю историю и обусловлены рядом причин, прежде всего, политических. Ламы-перерожденцы, или тулку, имеют огромное влияние среди верующих, которых традиционно много в Тибете. Поэтому неудивительно, что в Китае во все времена пытались влиять на данный вопрос на государственном уровне, что привело к созданию уникальной правовой базы, не имеющей аналогов в мире. Опыт Китая может быть взят на вооружение и другими государствами для регулирования вопросов, связанных с религией. Исходя из этого можно утверждать, что данная тема научных исследований не будет терять своей актуальности.

${ }^{1} \mathrm{O}$ мерах по управлению реинкарнациями живых Будд в тибетском буддизме: приказ Государственного комитета по делам религии КНP №5 от 13.07.2007. URL: http://www.gov.cn/gongbao/content/2008/content_923053.html (дата обращения: 20.11.2021). Текст: электронный.

${ }^{2} \mathrm{O}$ мерах по управлению реинкарнациями живых Будд в тибетском буддизме: приказ Государственного комитета по делам религии КНР №5 от 13.07.2007. URL: http://www.gov.cn/gongbao/content/2008/content_923053.html (дата обращения: 20.11.2021). Текст: электронный. 
Литература

1. Chen P. S. The Evolution and Political Significance of the Relationship between the Incarnation Hierarchy of the Dalai Lama and the Etiquette of the Qing Emperor// Journal of Chinese Culture. 2018. № 6. P. 21-24.

2. Richardson H. E. The Karma-Pa sect. A historical note//Journal of the Royal Asiatic Society. 1958. № 90. P. 139-164.

3. Manson C. Introduction to the Life of Karma Pakshi (1204/6-1283) // Bulletin of Tibetology. 2009. № 45. P. 25-52.

4. Wang S. A Brief History of Tibetan Buddhism. Beijing, BJ: China Tibetology Publishing House, 2010. P. 43.

5. Сабиров Рустам Тагирович Институт тулку в России: между отсутствием и присутствием // Сибирские исторические исследования. 2018. № 4. С. 202.

6. Wang S. A Brief History of Tibetan Buddhism. Beijing, BJ: China Tibetology Publishing House, 2010. P. 102.

7. Zhao Y. T. The Formation and Evolution of the Policy of Utilizing Tibetan Buddhism in the Early Qing Dynasty // Journal of Tibet Nationalities Institute.1984. № 1. P. 63-76.

8. Su F. X. Study on Tibetan Policy in Qing Dynasty. Beijing, BJ: Ethnic Publishing House, 1999. P. 134.

9. Laird, T. The story of Tibet: conversations with the Dalai Lama. New York: Grove and Atlantic, 2007. P. 205.

Статья поступила в редакцию 23.11.2021; одобрена после рецензирования 26.11.2021; принята к публикации 14.12.2021.

\section{LEGAL REGULATION OF THE ISSUES OF BUDDHIST LAMAS' REINCARNATION IN THE PRC: HISTORICAL AND LEGAL ASPECTS}

\section{Zhargal P. Gunzynov}

Senior Lecturer of Theory and History of Law and State Department, Dorzhi Banzarov Buryat State University

24a Smolina St., Ulan-Ude 670000, Russia gzzrl@yandex.ru

Abstract. The article deals with the legal regulation of the issues of Buddhist lamas' reincarnation in China. We have analyzed the different historical epochs and related legal acts, as well as the main reasons for a particular attention of the Chinese leadership to religious issues.

The study of this problem is of special interest as long as it is the case of regulating purely religious issues, which true nature is not completely clear to the present day, but at the same time it has a great influence on the state and public life.

Keywords: reincarnation, Buddhist law, Dalai Lama, Panchen Lama, Chinese law.

\section{For citation}

Gunzynov Zh. P. Legal Regulation of the Issues of Buddhist Lamas' Reincarnation in the PRC: Historical and Legal Aspects. Bulletin of Buryat State University. Law. 2021; 4: 16-22 (In Russ.).

The article was submitted 23.11.2021; approved after reviewing 26.11.2021; accepted for publication 14.12.2021. 